Research Article

\title{
Stator Current-Based Model Reference Adaptive Control for Sensorless Speed Control of the Induction Motor
}

\author{
Workagegn Tatek Asfu \\ Depertment of Electrical and Computer Engineering, Debre Berehan University, Debre Berhan, Ethiopia \\ Correspondence should be addressed to Workagegn Tatek Asfu; workagegntatek@gmail.com
}

Received 17 February 2020; Revised 15 September 2020; Accepted 25 September 2020; Published 15 October 2020

Academic Editor: Hassan Haes Alhelou

Copyright (C) 2020 Workagegn Tatek Asfu. This is an open access article distributed under the Creative Commons Attribution License, which permits unrestricted use, distribution, and reproduction in any medium, provided the original work is properly cited.

\begin{abstract}
This paper described that the stator current-based model reference adaptive system (MRAS) speed estimator is used for the induction motor (IM) indirect vector speed control without a mechanical speed sensor. Due to high sensitivity of motor parameters variation at low speed including zero, stability analysis of MRAS design is performed to correct any mismatch parameters value in the MRAS performed to estimate the motor speed at these values. As a result, the IM sensorless control can operate over a wide range including zero speed. The performance of the stator current-based MRAS speed estimator was analyzed in terms of speed tracking capability, torque response quickness, low speed behavior, step response of drive with speed reversal, sensitivity to motor parameter uncertainty, and speed tracking ability in the regenerative mode. The system gives a good performance at noload and loaded conditions with parameter variation. The stator current-based MRAS estimator sensorless speed control technique can make the hardware simple and improve the reliability of the motor without introducing a feedback sensor, and it becomes more important in the modern AC IM. The sensorless vector control operation has been verified by simulation on Matlab and experimentally using Texas Instruments HVMTRPFCKIT with TMS320 F28035 DSP card and 0.18 kw AC IM.
\end{abstract}

\section{Introduction}

Induction motors chosen for variable speed drives due to primarily low material and manufacturing cost and also reliable, associated with the squirrel cage induction motor, are proposed by $[1,2]$. As a result, induction motors are typically used in low and medium cost drive applications, which required moderate performance, such as conveyor belts, fans, and pumps. In [3-5], the authors proposed that accurate speed identification is required for all high-performance vectors that controlled IM drives. The speed identification of the IM can be performed by a shaft speed encoder. However, compared to speed estimation, a shaft speed encoder has several disadvantages such as an increase in cost, size, complexity, and maintenance requirements and a decrease in the reliability and robustness.

Shaft speed encoders are expensive and introduce reliability concerns for vector-controlled AC motor drives. The use of this encoder implies additional electronics, extra wiring, space, and careful mounting, which detracts from the inherent robustness of cage induction motors been proposed in [6]. Therefore, it has been a great interest in the research community in developing a high-performance induction motor drive that does not require a speed or position encoder for its operation. Different literatures proposed that the rotor speed of the induction motor has been estimated by various techniques. In [7], the rotor speed was estimated using angular velocity and slip calculation, the researchers used stator current and voltage as the reference model, and the performance of the system at operating (rated) speed was robust and simple to implement. However, the accuracy is not very good due to the great sensitivity to motor parameter variation. In [8], the state estimator for the induction motor was based on the extended Kalman filter. The estimation of rotor speed is by using nonlinear state estimation and is more robust to the IM parameter changes or identification errors but much more complicated in practical realization. The method required complexity mathematical analysis, and 
the system needs high speed computation memory. The solution for rotor speed estimation is based on stator current-based MRAS principle, in which an error vector is formed from the outputs of reference and adaptive models, models both dependent on different motor parameters. The error is driven to zero through adjustment of the parameter that influences one of the models. The MRAS approach has advantages such as simplicity and easy to implement and has direct physical interpretation. So, stator current-based MRAS solves the problem due to aging, unmodel dynamics, and parameter variation even at low speed.

The stator current-based MRAS speed estimator has been designed and test through various software tools. In this paper, design and implementation of an adaptive estimator using the Matlab simulation and implementation using Texas Instruments TMS320F28035 control card on the general purpose $\mathrm{AC}$ induction motor was performed.

\section{Indirect Field-Oriented Control}

In the indirect field-oriented control (IFOC), the rotor flux angle is being measured indirectly, instead of using air gap flux sensors. IFOC estimates the rotor flux by computing the slip speed. The stationary $d$ and $q$ axes are fixed on the stator, and the rotor $d$ and $q$ axes are fixed on the rotor flux. The synchronous $d$ and $q$ axes are rotating at a synchronous speed, and so, there is a slip difference between the rotor speed and the synchronous speed. In order to ensure decoupling between the rotor flux and the torque, the torque component of the current should be aligned with the synchronous $q$-axis, and the stator flux component of current should be aligned with the synchronous $d$-axis.

In [9], the stator and rotor voltage equation of the induction motor in the field orientation synchronous reference frame was described. The general block diagram of the stator current-based MRAS speed estimator is shown in Figure 1.

\section{Model Reference Adaptive System Design}

Speed estimation methods using MRAS can be classified into various types according to the state variables. The most commonly used are the rotor flux-based MRAS, reactive power MRAS, back emf-based MRAS, and stator currentbased MRAS. In $[10,11]$, in the rotor flux-based MRAS, the rotor flux is used as an output value for the model to estimate the rotor speed. In rotor flux-based MRAS, the presence of an open integration in the stator leads to problems with initial conditions and drift. A low-pass filter may be used instead of the pure integration; however, it has a degrading effect on speed estimation at low speeds and introduces time delay. The model reference adaptive approach based on back emf rather than the rotor flux offers an alternative to avoid the problem of pure integration. The pure integration is avoided in this approach, and there are no low-pass filters that create a bandwidth limit. A more severe source of inaccuracy is a possible mismatch of the reference model parameters and particularly of the stator resistance proposed by Rashed and Stronach in [12]. The solution for these problems is using the stator current-based MRAS speed estimator based on the comparison between the measured stator current of the IM and the estimated current obtained from the stator current model, which is used to estimate the rotor speed.

As shown in Figure 2, the stator current-based MRAS speed estimation structure consists basically of a reference model, adjustable model, and an adaptive mechanism. The reference model, which is independent of the rotor speed, calculates the state variable $\left(i_{s \alpha}, i_{s \beta}\right)$ from the induction motor model and the adjustable model, which is dependent on the rotor speed, and estimates the state variables $\left(\hat{i}_{s \alpha}, \hat{i}_{s \beta}\right)$ and $\left(\widehat{\varphi}_{r \alpha}, \widehat{\varphi}_{r \beta}\right)$. The error between measured and estimated state variables is then used to drive an adaptation mechanism, which generates the estimated speed, for the adjustable model as shown in the block diagram of Figure 2.

\subsection{Stator Current-Based MRAS Speed Estimator Design.}

The stator current-based MRAS speed estimator design is based on the comparison between the measured stator current of the IM and the estimated current obtained from the flux current model as shown in Figure 3. Using stator and rotor voltage and current equation, the mathematical model of the rotor flux and the stator current are estimated in stationary reference frames as follows.

$$
\frac{\mathrm{d}}{\mathrm{d} t} \hat{i}_{s \beta}=\frac{1}{\sigma L_{s}}\left(v_{s \beta}-R_{s} \widehat{i}_{s \beta}-\frac{L_{m}^{2}}{L_{r} T_{r}} \widehat{i}_{s \beta}+\frac{L_{m}}{L_{r} T_{r}} \widehat{\varphi}_{r \beta}+\frac{L_{m}}{L_{r}} \widehat{\omega}_{r} \widehat{\varphi}_{r \alpha}\right),
$$

$$
\frac{\mathrm{d}}{\mathrm{d} t} \widehat{i}_{s \alpha}=\frac{1}{\sigma L_{s}}\left(v_{s \alpha}-R_{s} \widehat{i}_{s \alpha}-\frac{L_{m}^{2}}{L_{r} T_{r}} \widehat{i}_{s \alpha}+\frac{L_{m}}{L_{r} T_{r}} \widehat{\varphi}_{r \alpha}+\frac{L_{m}}{L_{r}} \widehat{\omega}_{r} \widehat{\varphi}_{r \beta}\right),
$$

$$
\begin{aligned}
& \frac{\mathrm{d}}{\mathrm{d} t} \widehat{\varphi}_{r \beta}=\frac{L_{m}}{L_{r}} \widehat{i}_{s \beta}-\frac{1}{T_{r}} \widehat{\varphi}_{r \beta}+\widehat{\omega}_{r} \widehat{\varphi}_{r \alpha}, \\
& \frac{\mathrm{d}}{\mathrm{d} t} \widehat{\varphi}_{r \alpha}=\frac{L_{m}}{L_{r}} \widehat{i}_{s \alpha}-\frac{1}{T_{r}} \widehat{\varphi}_{r \alpha}-\widehat{\omega}_{r} \widehat{\varphi}_{r \beta} .
\end{aligned}
$$

In the stator current-based MRAS rotor speed estimator, the adaptation algorithm is based on the error between estimated and measured stator current based on the Lyapunov function. The adaptation mechanism can be derived from the adaptive stator current, and rotor flux estimator is constructed as follows. Considering the Lyapunov function candidate [13], rearrange equations (1)-(4) in the matrix form:

Let, $\dot{x}=A x+B \overrightarrow{v_{s}}$ and $y=C x$, where system matrix $\mathrm{A}$ is written as follows 


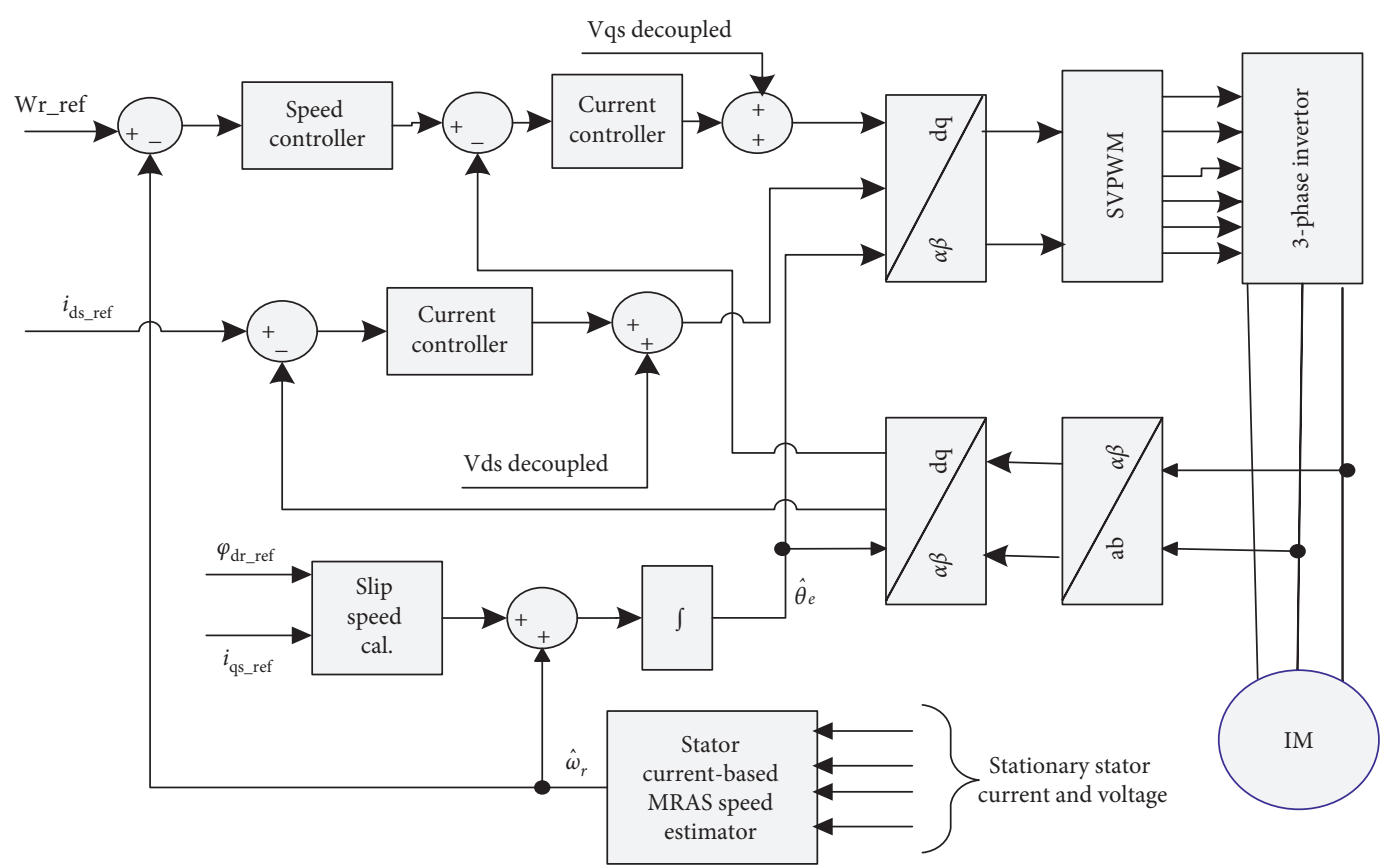

Figure 1: General block diagram of MRAS-based sensorless speed control of the induction motor.

$A=\left[\begin{array}{cccc}\frac{-1}{\sigma L_{s}}\left(R_{s}+\frac{L_{m}^{2}}{L_{r} T_{r}}\right) & 0 & \frac{1}{\sigma L_{s}} \frac{L_{m}}{L_{r} T_{r}} \frac{1}{\sigma L_{s}} \frac{L_{m}}{L_{r}} \widehat{\omega}_{r} \\ 0 & \frac{-1}{\sigma L_{s}}\left(R_{s}+\frac{L_{m}^{2}}{L_{r} T_{r}}\right) & \frac{-1}{\sigma L_{s}} \frac{L_{m}}{L_{r}} \widehat{\omega}_{r} & \frac{1}{\sigma L_{s}} \frac{L_{m}}{L_{r} T_{r}} \\ \frac{L_{m}}{T_{r}} & 0 & \frac{-1}{T_{r}} & \widehat{\omega}_{r} \\ 0 & \frac{L_{m}}{T_{r}} & \widehat{\omega}_{r} & \frac{-1}{T_{r}}\end{array}\right]$

$B=\frac{-1}{\sigma L_{s}} \cdot C^{T}$

$C=\left[\begin{array}{llll}1 & 0 & 0 & 0 \\ 0 & 1 & 0 & 0\end{array}\right]$

$\frac{\mathrm{d} v}{\mathrm{~d} t}=\left\{\varepsilon^{T}\left[A^{T}+A\right] \varepsilon-2\left(\omega_{r}-\widehat{\omega}_{r}\right)\left[k\left(\varepsilon_{i \alpha} \widehat{\varphi}_{r \beta}-\varepsilon_{i \beta} \widehat{\varphi}_{r \alpha}\right)-\frac{1}{\gamma} \frac{\mathrm{d}}{\mathrm{d} t} \widehat{\omega}_{r}\right]\right\}$,

$$
\varepsilon^{T}\left[A^{T}+A\right] \varepsilon<-Q
$$

$y=C \widehat{x}$ $\begin{aligned} & \text { Let } \varepsilon_{i \alpha}=i_{\alpha s}-\widehat{i}_{\alpha s}, \text { and } \varepsilon_{s}=i_{s}-\widehat{i}_{s} \text {, where } i_{s}=\left[\begin{array}{c}i_{\alpha s} \\ i_{\beta s}\end{array}\right] \text {, } \\ & \varepsilon_{i \beta}=i_{\beta s}-\hat{i}_{\beta s} \text {, and } \varepsilon_{\omega}=\omega_{r}-\widehat{\omega}_{r} .\end{aligned}$

$v=v_{1}+v_{2}$. Let $v_{1}=\varepsilon^{T} \varepsilon$ and $v_{2}=\varepsilon_{\omega}^{2} / \gamma$, and the derivative of this Lyapunov candidate function written as $x-\hat{x}$.

The derivative of this Lyapunov candidate function written as $\mathrm{Q}=\rho I_{n}$ and $\rho>0$, and it is an identity matrix.
Using the Lyapunov stability of the adaptive estimator has been proved if two conditions are fulfilled. The eigenvalues of the estimator are selected to have negative real parts, so that the states of the estimator will converge to the desired states of the estimated system. The term in factor of $\left(\omega_{r}-\widehat{\omega}_{r}\right)$ in equation (5) must be zero. The expression of the derivative of estimated speed becomes

$$
\begin{aligned}
k\left(\varepsilon_{i \alpha} \widehat{i}_{s \beta}-\varepsilon_{i \beta} \widehat{\varphi}_{r \alpha}\right)-\frac{1}{\gamma} \frac{\mathrm{d}}{\mathrm{d} t} \widehat{\omega}_{r} & =0, \\
\frac{\mathrm{d}}{\mathrm{d} t} \widehat{\omega}_{r} & =\gamma k\left(\varepsilon_{i \alpha} \widehat{\varphi}_{r \beta}-\varepsilon_{i \beta} \widehat{\varphi}_{r \alpha}\right), \\
\widehat{\omega}_{r} & =M \int\left(\varepsilon_{i \alpha} \widehat{\varphi}_{r \beta}-\varepsilon_{i \beta} \widehat{\varphi}_{r \alpha}\right) \mathrm{d} t .
\end{aligned}
$$

However, this adaptive law of the speed has been obtained by adjusted $M$ (finite positive constant). For improving the dynamic of this estimator during the transitory phase of the rotor speed, estimate the speed by a large PI regulator; so, it requires a supplementary term proportional. Then,

$$
\widehat{\omega}_{r}=\mathrm{ki} \int\left(\varepsilon_{i \alpha} \widehat{\varphi}_{r \beta}-\varepsilon_{i \beta} \widehat{\varphi}_{r \alpha}\right) \mathrm{d} t+\mathrm{kp}\left(\varepsilon_{i \alpha} \widehat{\varphi}_{r \beta}-\varepsilon_{i \beta} \widehat{\varphi}_{r \alpha}\right)
$$

where $k_{i}$ and $k_{p}$ are the adaptive gains for the speed estimator.

\subsection{Stability Analysis of the Stator Current-Based MRAS Speed} Estimator. The stability analysis of the stator current-based MRAS speed estimator is tested from the point of the IM and 


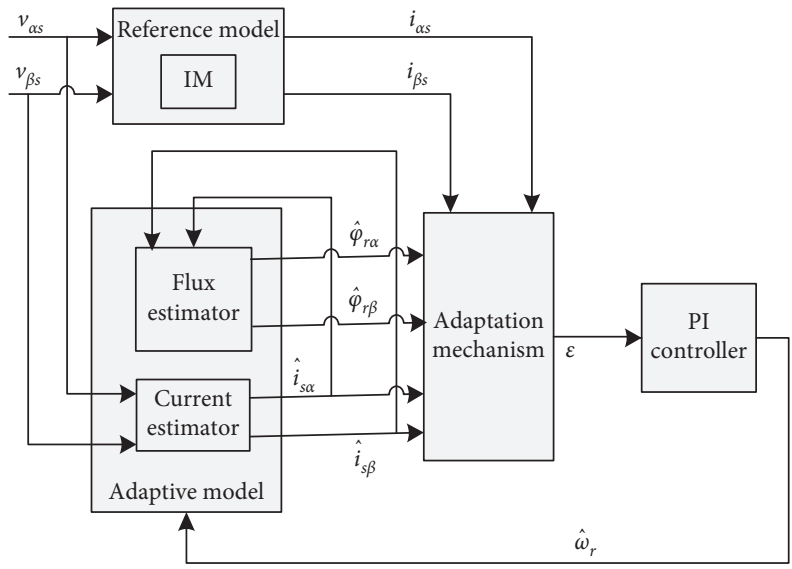

FIGURE 2: General block diagram of the stator current-based MRAS speed estimator.

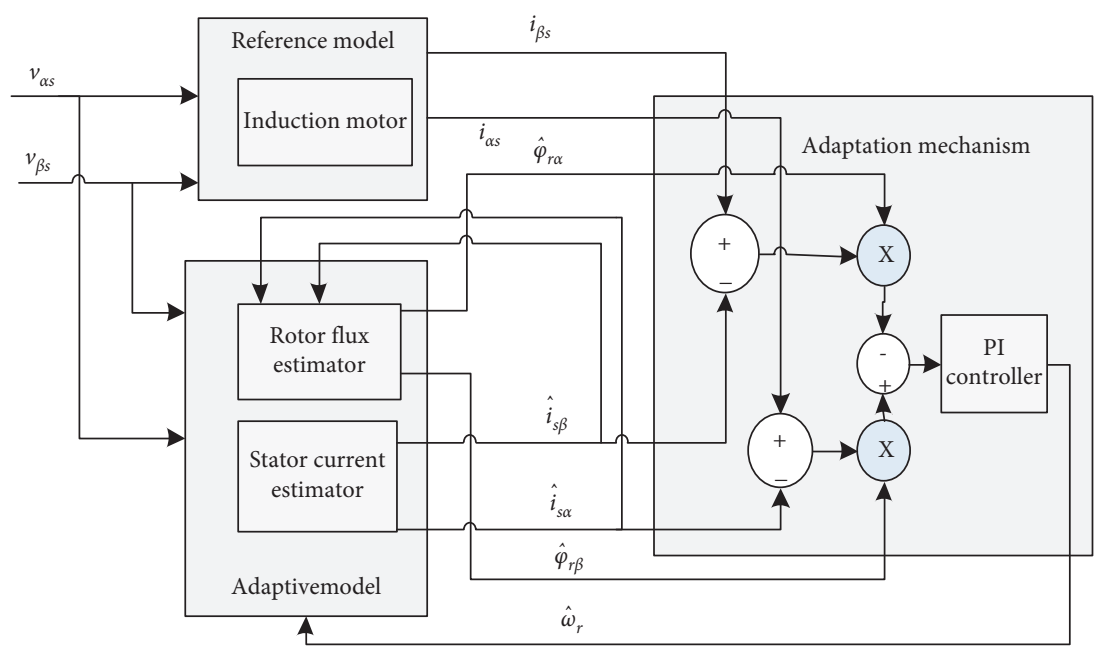

FIGURE 3: Adaptation mechanisms for the stator current-based MRAS speed estimator.

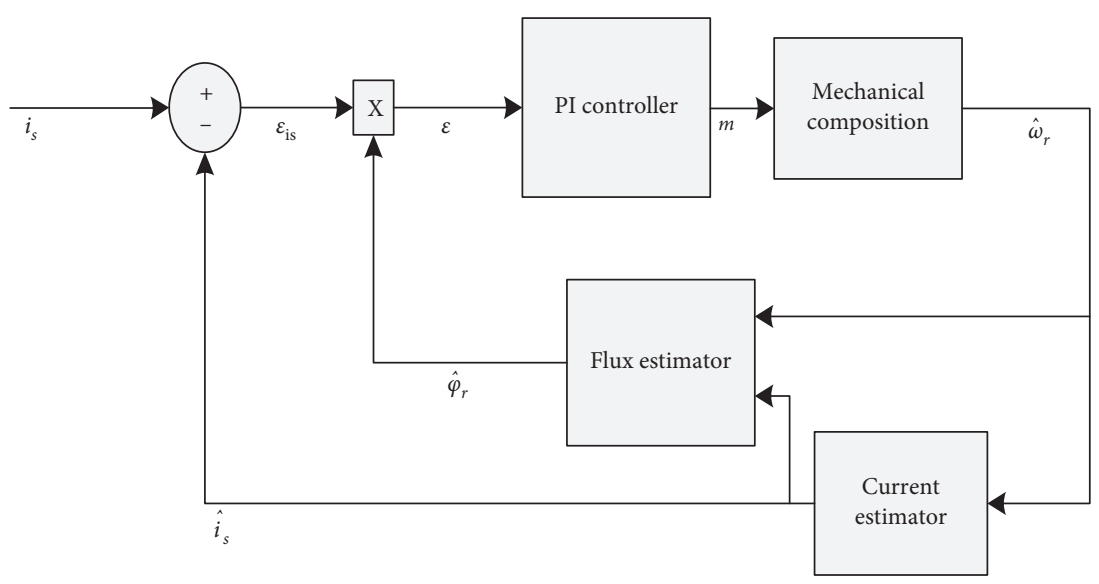

FIgURE 4: Closed loop stator current-based MRAS speed estimator with mechanical compensation.

PI controller parameter changes, on the basis of the estimator transfer function. From the point of view of the rotor speed estimation, the stator current-based MRAS speed estimator can be analyzed as a system controlled by the signal, which is the combination of the stator current and the rotor flux used in the adaptation loop. To find the value of 
the PI adaptive gains, analyze the closed loop transfer function of the stator current-based MRAS speed estimator (Figure 4).

The mechanical model of the system at stationary reference frame is obtained as follows.

$$
\frac{\mathrm{d}}{\mathrm{d} t} \widehat{\omega}_{r}=\frac{3 \mathrm{pL}_{m}}{4 \mathrm{JL}}\left(\varphi_{\alpha r} i_{\beta s}-\varphi_{\beta r} i_{\alpha s}\right)-\frac{f}{J} \omega_{r}-\frac{\mathrm{Tl}}{J}
$$

In order to drive the PI controller parameter, a linearized transfer function between $m_{(s)}$ and $\varepsilon_{(s)}$ is obtained. Using small signal analysis under the assumption of field orientation, the difference between the measured and the estimated value, with the operating point, is written as

$$
\begin{aligned}
& \Delta y=C \Delta x=C(\mathrm{SI}-A)^{-1} \Delta A x_{0}, \\
& \Delta \dot{x}=A \Delta x+\Delta A x_{0},
\end{aligned}
$$

where $\Delta x=(x-\hat{x})$, and $x_{0}=\left[i_{\mathrm{d} s 0} i_{\mathrm{qs} 0} \varphi_{\mathrm{dr} 0} \varphi_{\mathrm{qr} 0}\right]^{T}$.

The system matrix $\mathrm{A}$ is expressed as follows, considering the rotor speed as the only variable parameter.

$$
\begin{aligned}
& \Delta A=\left[\begin{array}{cccc}
0 & 0 & 0 & a \\
0 & 0 & -a & 0 \\
0 & 0 & 0 & -1 \\
0 & 0 & 1 & 0
\end{array}\right] \Delta \omega_{r}, \\
& \text { where, } a=\frac{1}{\sigma L_{s}} \frac{L_{m}}{L_{r}} \text {, } \\
& \Delta y=\left[\begin{array}{l}
i_{\alpha s}-\widehat{i}_{\alpha s} \\
i_{\beta s}-\widehat{i}_{\beta s}
\end{array}\right] \\
& \operatorname{adj}(\mathrm{SI}-A)=\left[\begin{array}{llll}
a_{11} & a_{12} & a_{13} & a_{14} \\
a_{12} & a_{22} & a_{23} & a_{24} \\
a_{31} & a_{32} & a_{33} & a_{34} \\
a_{41} & a_{42} & a_{43} & a_{44}
\end{array}\right] \text {, } \\
& {\left[\begin{array}{l}
\frac{\Delta i_{\alpha s}}{\Delta \omega_{r}} \\
\frac{\Delta i_{\beta s}}{\Delta \omega_{r}}
\end{array}\right]=C(\mathrm{SI}-A)^{-1}\left[\begin{array}{cccc}
0 & 0 & 0 & a \\
0 & 0 & -a & 0 \\
0 & 0 & 0 & -1 \\
0 & 0 & 1 & 0
\end{array}\right]}
\end{aligned}
$$

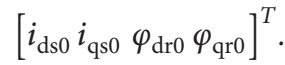

Then, substitute equation (12) into equation (13), and solving $\Delta w_{r}$ from the mechanical model, the transfer function of $m_{(s)}$ and $\varepsilon_{(s)}$ is obtained.

From equation (12) and the adjoint of (SI $-A)$,

$$
\varepsilon=-\frac{\left(a_{24}-a a_{22}\right)}{|\mathrm{SI}-A|} \widehat{\varphi}_{\alpha r 0}^{2} \Delta \omega_{r}
$$

Then, the transfer function between $\varepsilon_{(s)}$ and $m_{(s)}$ is obtained as

$$
\frac{\varepsilon(s)}{m(s)}=\left\{-\frac{\left(a_{24}-a a_{22}\right)}{|S I-A|} \frac{1}{(s+(f / J))} \frac{p}{2 J} \widehat{\varphi}_{\alpha r 0}^{2}\right\} .
$$

Let $G(s)$ and $\varepsilon(s) / m(s)$ are then the simplified closed loop block diagram of the stator current-based MRAS speed estimator as shown in Figure 5.

$$
\frac{\omega_{r}}{\widehat{\omega}_{r}}=\left\{\frac{\left(G_{(s)}\left(\mathrm{kp}_{\mathrm{mras}}+\left(\mathrm{ki}_{\mathrm{mras}} / s\right)\right)\right)}{1+\left(G_{(s)}\left(\mathrm{kp}_{\mathrm{mras}}+\left(\mathrm{ki}_{\mathrm{mras}} / s\right)\right)\right)}\right\} .
$$

The design of $k_{p}$ and $k_{i}$ is introduced to ensure stability, error tracking, and robust operation. The design criteria for this adaptive PI controller are performed using Matlab/ SISOTOOL, by using the transfer function of the plant and set the time domain constraint. The constraint considered in this design is that the percentage of overshoot, settling time, and rise time are less than five percentage, less than two second, and less than two second, respectively.

As shown in Figure 6, the design is selected to ensure that all the poles and zeros are located in the left hand side of the $s$-plane, and this allows for the required fast and stable response.

\section{Simulation Results and Discussion}

The proposed control system represented in Figure 1 is designed for simulation by the Matlab/Simulink model. Simulation results are presented and discussed to show the effectiveness of the proposed drive system based on the stator current-based MRAS speed estimator and IFOC at different operating conditions. For studying the performances of proposed system, a series of simulations and measurements have been carried out. In this respect, the dynamic response of the proposed speed estimation algorithm is studied under different speed commands.

4.1. Simulation Results. The simulation result of MRASbased sensorless speed control of the induction motor drive was carried out to assess its performance. Knowledge of motor's parameter is important for this simulation, since the estimator is highly parameter dependent, and the effect of the parameter variation was tested based on different conditions that are put on their effects on robustness of the speed control.

The first simulation result for the MRAS-based sensorless speed control of the induction motor is the threephase stator current, which is generated by the three-phase voltage source inverter. This three phase voltage source inverter is controlled by SVPWM blocks for appropriate stator current generation. These three phases of current should be of equal magnitude and $120^{\circ}$ phase shift with each other for appropriate rotating flux generation as shown in Figure 7. 


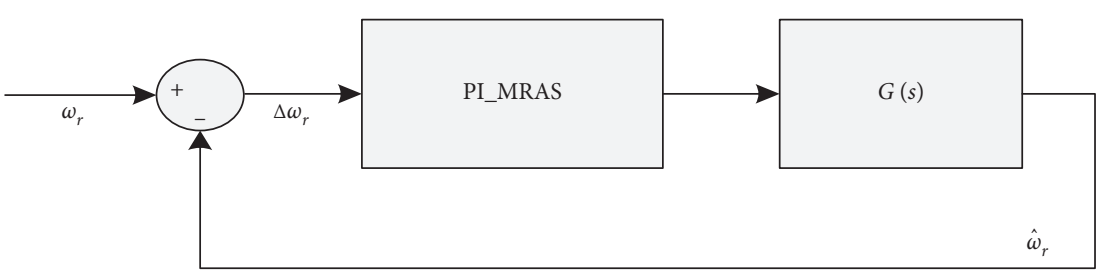

FIgURE 5: Closed loop block diagram of the stator current-based MRAS speed estimator.

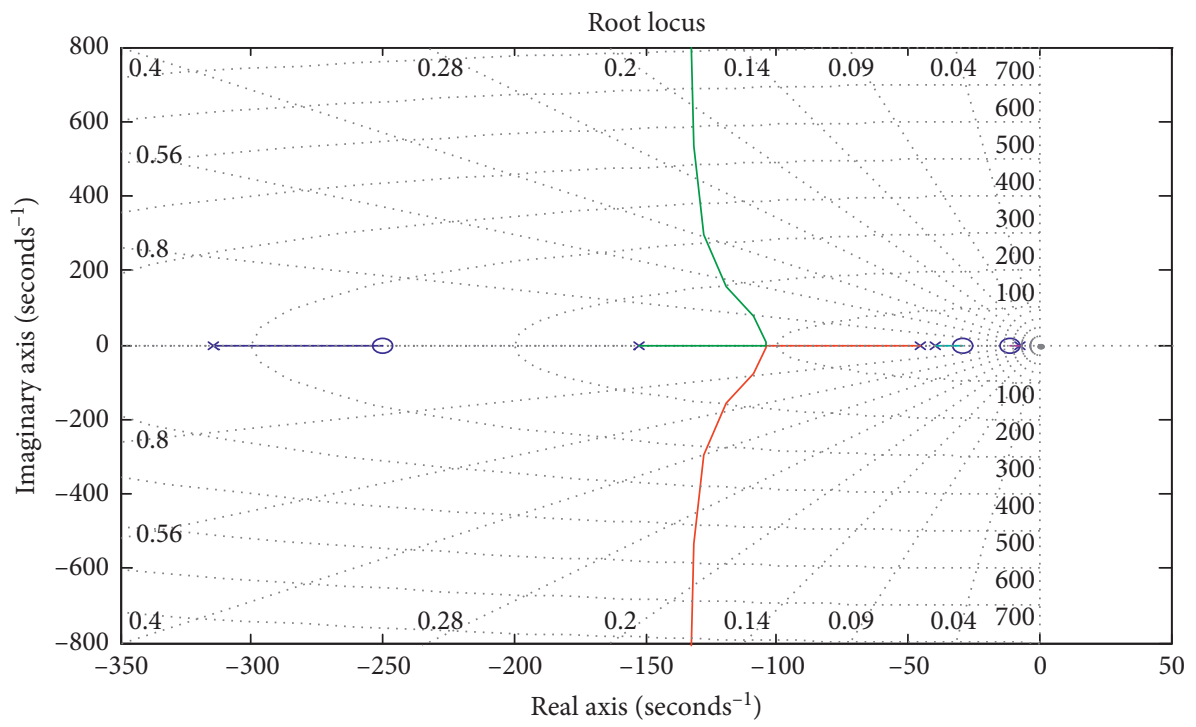

FIgURE 6: Root locus of the closed loop adaptive control system.

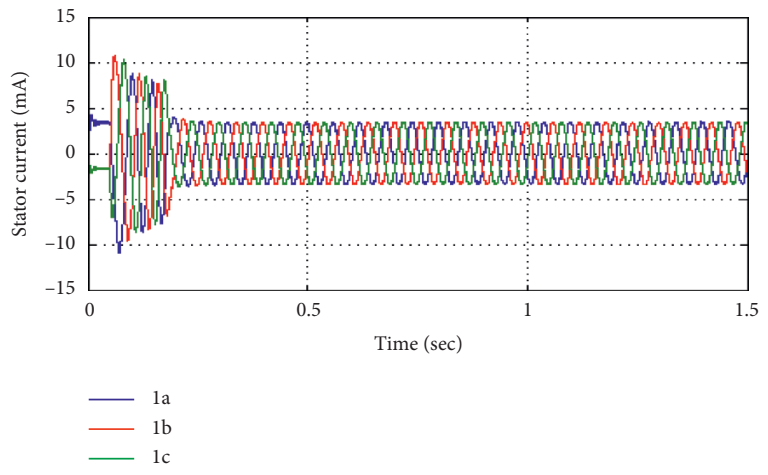

FIgURE 7: Three-phase stator current at $100 \mathrm{rad} / \mathrm{s}$.

As it has been seen from the Figure 7, the appropriate stator phase current is generated with good accuracy. Hence, the system can feed the appropriate stator voltage to the motor. If the voltage applied to the motor is applied with appropriate magnitude and frequency, the speed of the motor is respected as a set to the reference value.

The simulation results of the proposed stator currentbased MRAS speed estimator for sensorless speed control of the induction motor drive is discussed in terms of set point tracking capability, torque response quickness, low speed behavior, step response of drive with speed reversal, sensitivity to motor parameter uncertainty, and speed tracking ability in the regenerative mode.
4.1.1. Set Point Tracking Capability. It is always crucial to know the performance of an estimator based on the ability of the estimated speed to converge the actual value, especially during the transient response. This criterion has been well accepted as a primary indicator when benchmarking the performance of a sensorless speed estimator. Using the same parameters in the induction motor and the stator current-based MRAS speed estimator, the tracking performance of the estimator can be examined by changing the speed reference of the system. As shown in Figures 8(a) and 8(c), the proposed estimator tracks both the step and square signals reference input. This shows the tracking performance of the estimator, and the actual speed to the reference speed can be examined by changing the reference of the system with the maximum steady state error of $0.0027 \%$ and good transient performance with rise time less than 0.1 second. As shown in Figure 8(b), the estimated angle follows with the actual angle with the maximum error of $0.1 \mathrm{rad}$. Figure 9(a) shows the variable speed driving of the induction motor with step speed response, the actual, and the estimated speed track the reference speed at every 0.13 seconds. As shown in Figure 9(b), the actual speed and the estimated speed follow the reference with variable step input for 0.75 seconds and the input change to sine to check its tracking capability for different inputs. From this result, the proposed system operates for different 


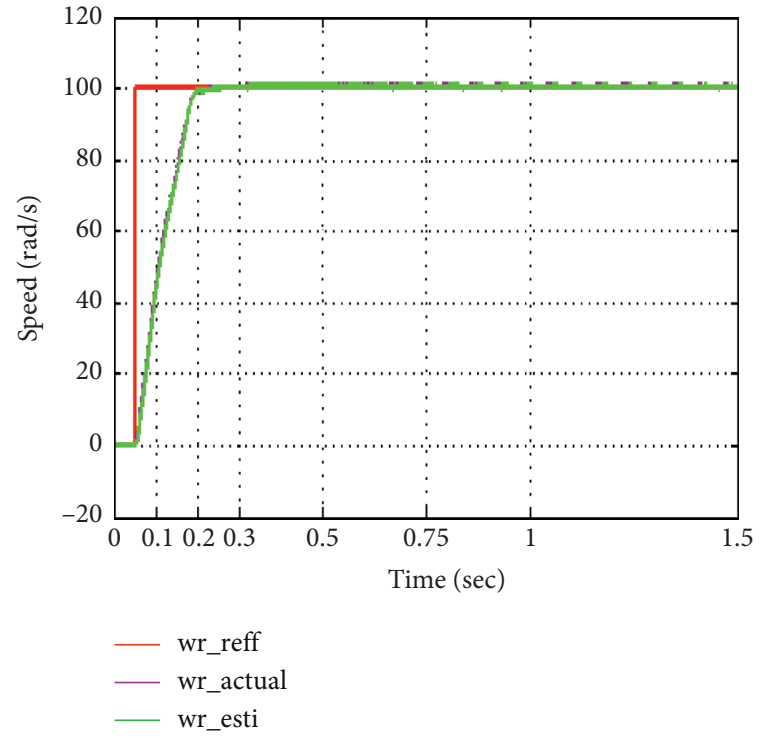

(a)

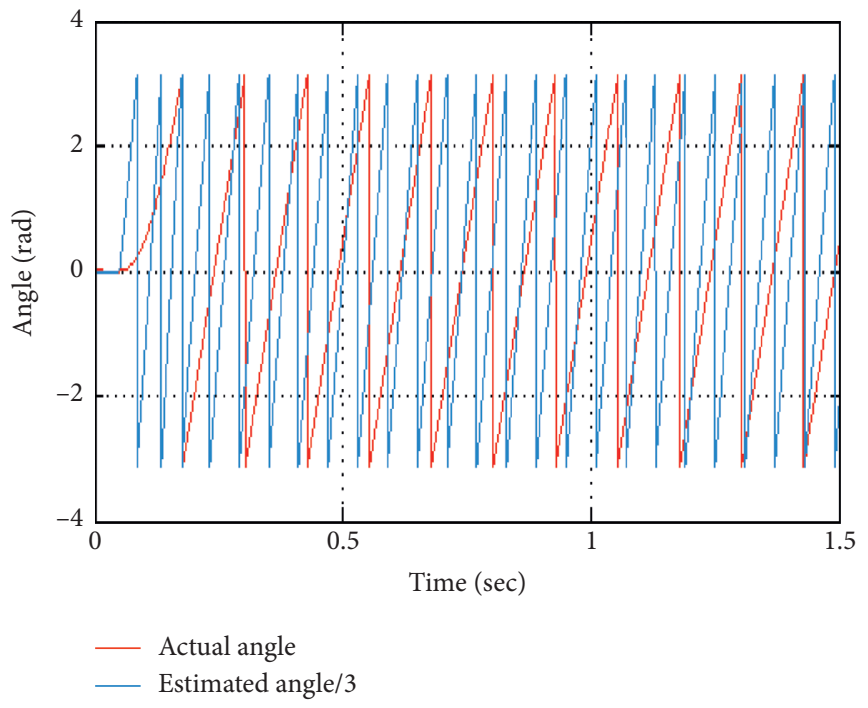

(b)

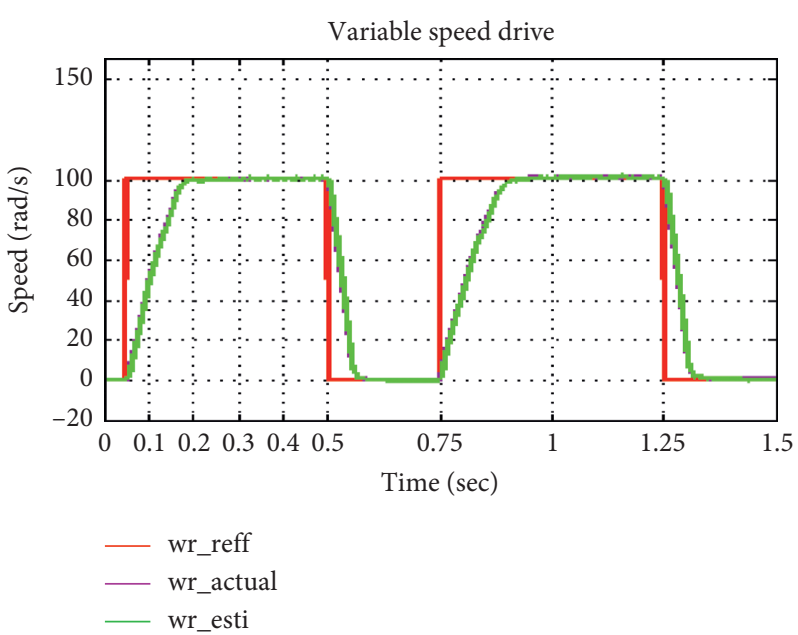

(c)

FIGURE 8: Speed response for square and step reference speed in $\mathrm{rad} / \mathrm{s}$ and the estimated angle.

inputs with a good accuracy of steady state and transient responses.

4.1.2. Torque Response Quickness. To find the torque response quickness, the motor is started with $1 \mathrm{Nm}$ load torque, and this value is increased to $2 \mathrm{Nm}$, and after 0.2 second, this results in a drop in the motor speed. This happens because of the mismatch in the torques, i.e., the developed torque is less than the load torque. To compensate for this mismatch, the controller increases the developed torque; then, the motor speed increases and comes back to the set point as shown in Figure 10.

4.1.3. Low and Zero Speed Behavior. The aim of this test is to evaluate the performance of the stator current-based MRAS speed estimator at low speed. Figure 11(a) shows that the estimated speed follows the actual speed exactly, the reference speed is very close with the steady state error of $0.024 \mathrm{rad} / \mathrm{s}$, and a good transient performance rise time less than 0.1 second. There is also good field orientation down to zero speed as shown in Figure 11(b). This means that the system is stable at zero spee $\widehat{\omega}_{r} \mathrm{~d}$, and continuous operation is possible. There is a short period, and the $\omega_{r \text {-act }}$ and settle to their respective steady state values.

4.1.4. Step Response of Drive with Speed Reversal. Figure 12 shows the simulation result for speed reversal in step input. The motor reference speed is changed from $75 \mathrm{rad} / \mathrm{s}$ to $-35 \mathrm{rad} / \mathrm{s}$ at 0.5 seconds, and again, speed is set to $75 \mathrm{rad} / \mathrm{s}$ at 1 second. The result shows that the actual and estimated speed takes 0.09 second to follow the reference speed with good accuracy transient response. Reference speed and actual speeds are plotted in the same scale to observe the accuracy of the stator current-based MRAS speed estimator. 

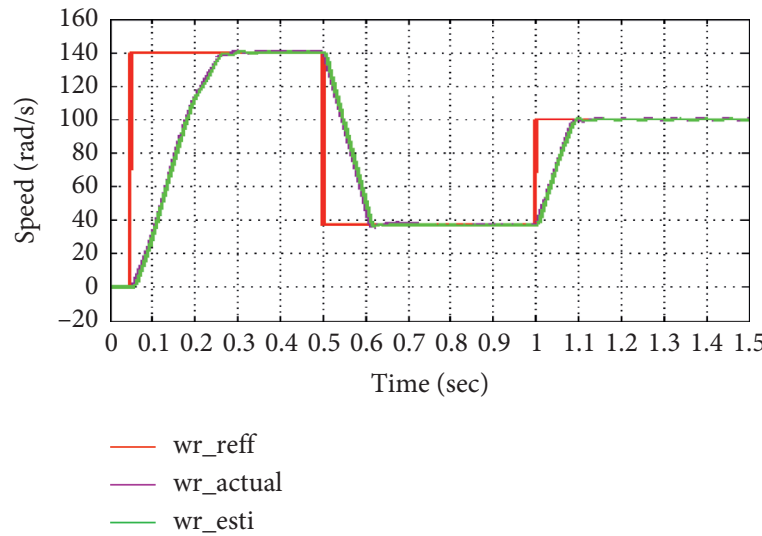

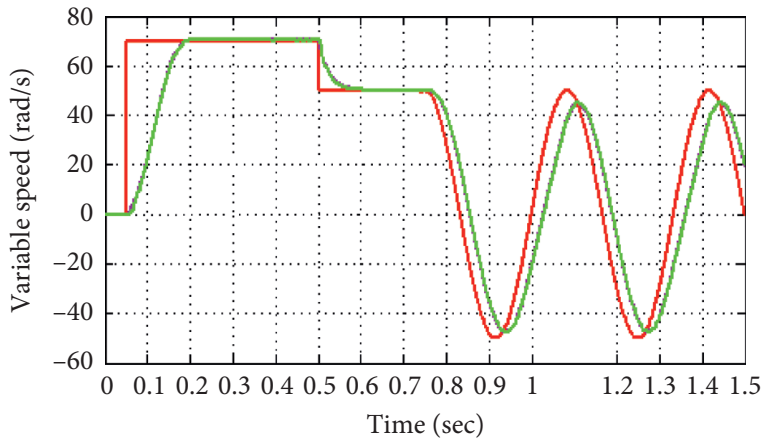

_ wr_reff

- wr_actual

_ wr_esti

(a)

(b)

Figure 9: Variable speed step response in $\mathrm{rad} / \mathrm{s}$ with a load torque of $2 \mathrm{Nm}$.

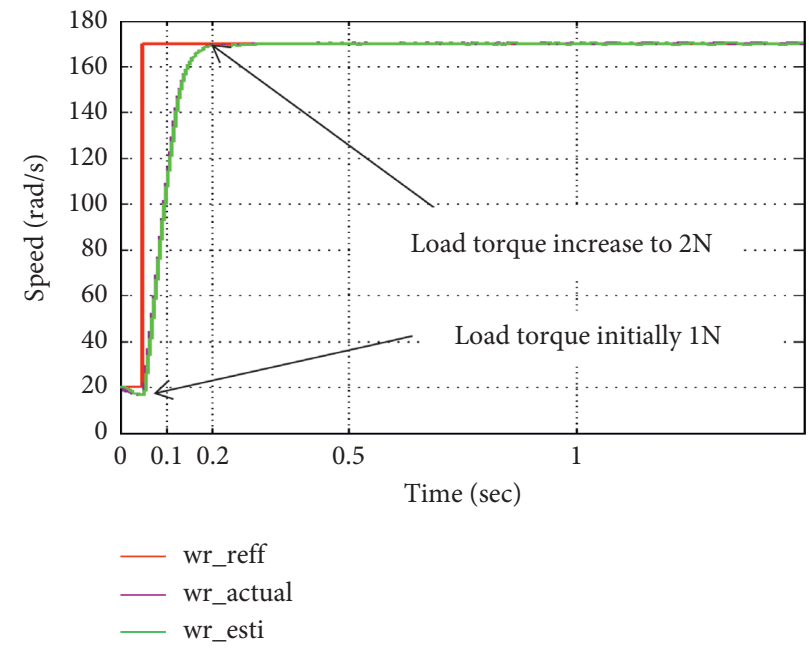

FIgURE 10: Load torque effect on stator current-based MRAS.
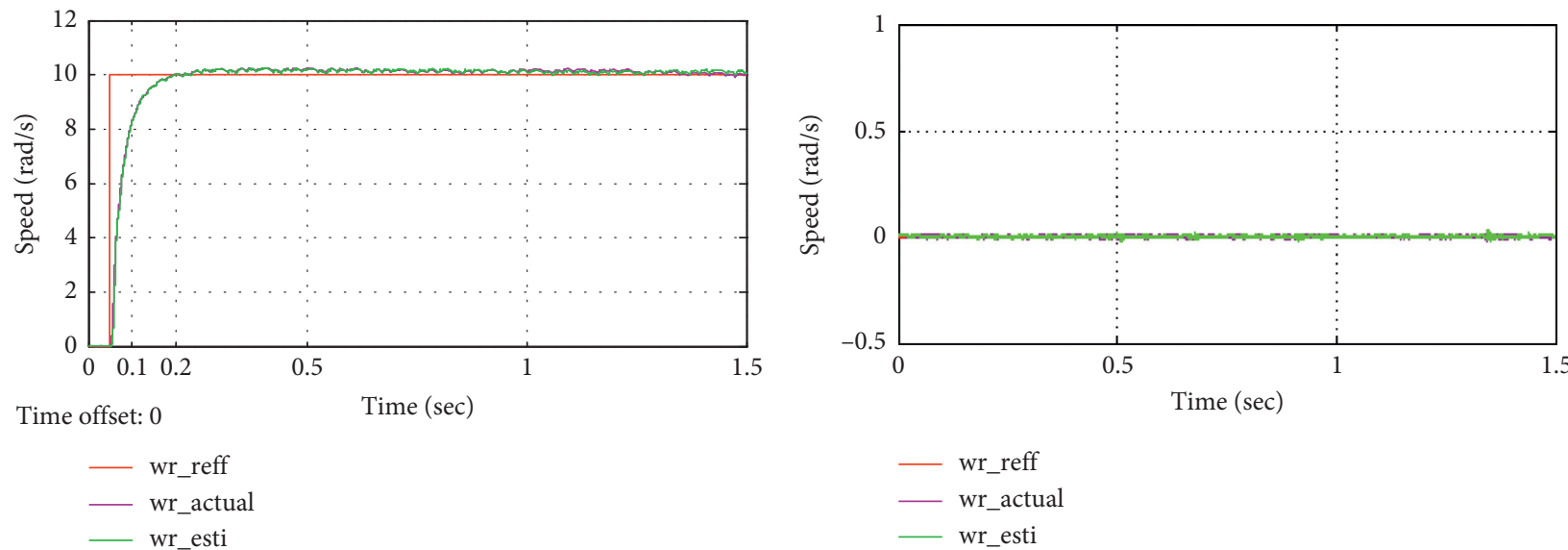

(a)

(b)

Figure 11: Step response for $10 \mathrm{rad} / \mathrm{s}$ and zero $\mathrm{rad} / \mathrm{s}$ speed response with no load torque. 


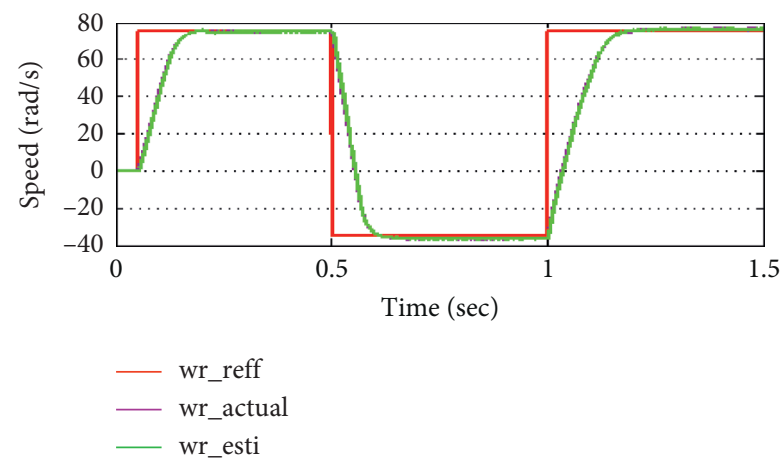

Figure 12: Step response of drive with speed reversal with load.

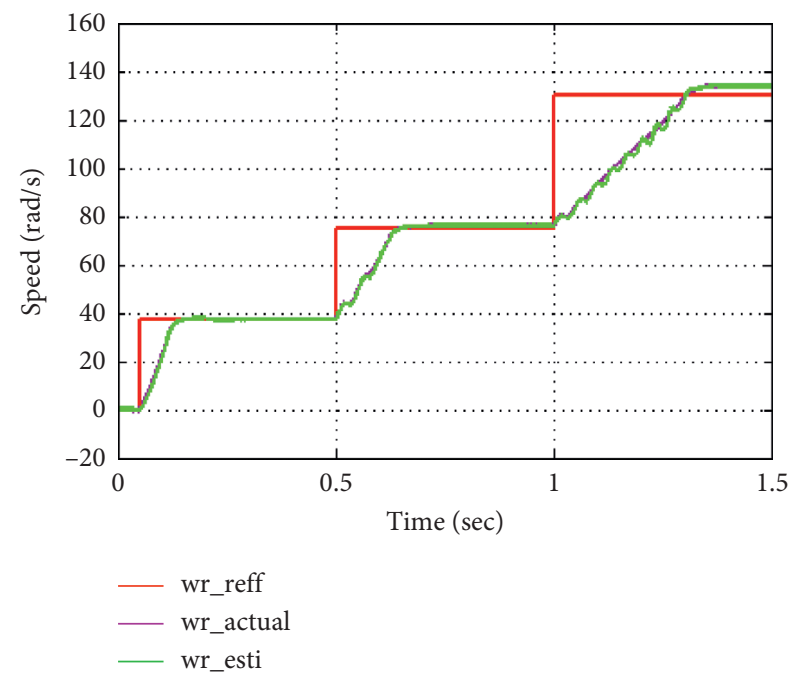

FIGURE 13: 75\% increase of all parameters from their nominal value for different rotor speeds.

4.1.5. Parameter Sensitivity. The sensitivity to the motor parameters change has been tested for three reference speeds, namely, $100 \%, 50 \%$, and $25 \%$ of the nominal speed; parameters $R_{s}, L_{s}, R_{r}$, and $L_{r}$ have been changed by $75 \%$ from their nominal value. As shown in Figure 13, the sensitivity to motor parameter changes of the sensorless field oriented control with the stator current-based MRAS speed estimator is less sensitive to motor parameter variation. As shown in Figure 14, when the motor parameters decrease by $75 \%$ of their nominal value, the estimated speed exactly follows the actual speed and closely to the reference speed with a good accuracy of transient with rise time less 0.1 second with steady state error of less than $0.028 \mathrm{rad} / \mathrm{s}$. In Figure 14, the speed estimator is much less sensitive to the IM parameter changes at low speed, and the sensitivity increases to some extent when the speed is near to its nominal speed, i.e., $140 \mathrm{rad} / \mathrm{s}$.

The effect of stator and rotor resistance on the stator current-based MRAS speed estimator. Assume that the rotor and stator resistance vary by increasing $50 \%$ and decreasing $50 \%$ with their nominal value, and the other parameters are constant, with the speed $100 \%, 50 \%$, and $25 \%$ of the rated value. As shown in Figures 15 and 16, when the stator resistance varies by $50 \%$ of its nominal value, the estimated

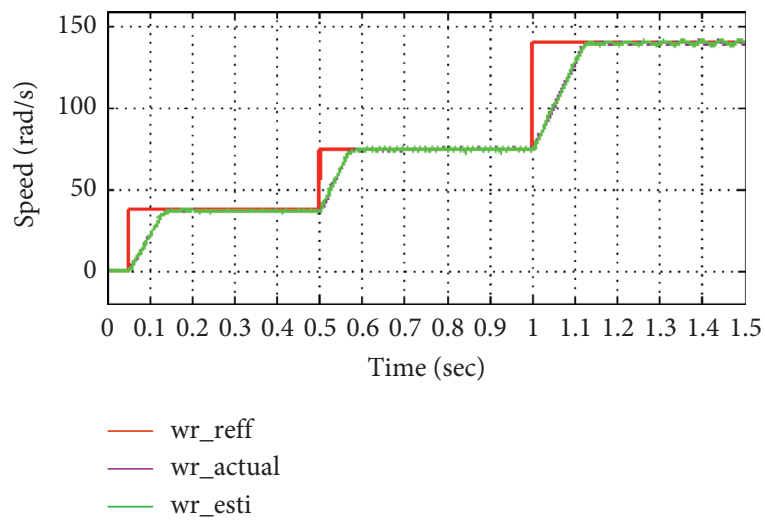

FIGURE 14: 75\% decrease of all parameters from their nominal value for different rotor speeds with load torque.

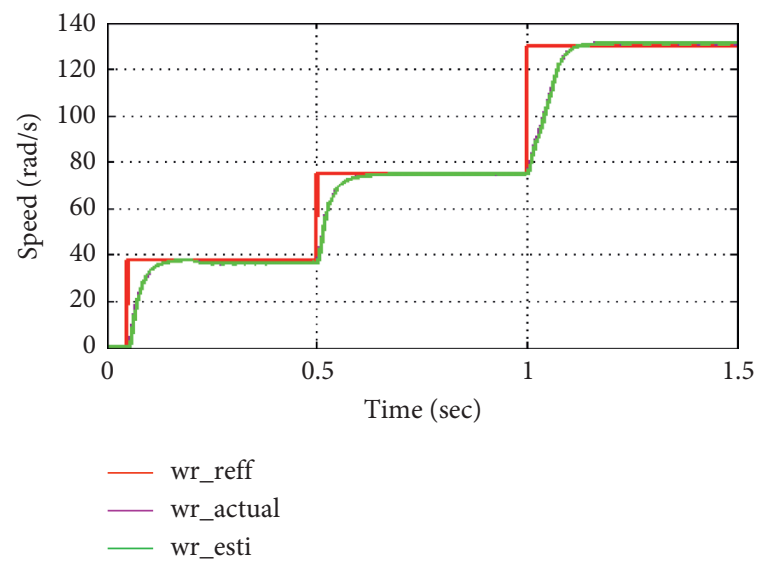

FIgURE 15: 50\% decrease of $R_{s}$ from its nominal value for different rotor speeds.

speed exactly follows the actual speed and closely to the reference speed with a good accuracy of transient and steady state responses. As shown in Figures 17 and 18, when rotor resistance changes 50\% from its nominal value, it has a good accuracy while the motor is running at low speed, while increasing the speed near to the nominal value, settling time and rise time increase compared to the lower speed. From this result, further increasing of the rotor resistance may affect the motor speed, while it runs near to its nominal speed. 




FIGURE 16: 50\% increase of $R_{s}$ from its nominal value for different rotor speeds.



Figure 17: 50\% decrease of $R_{r}$ from its nominal value for different rotor speeds.

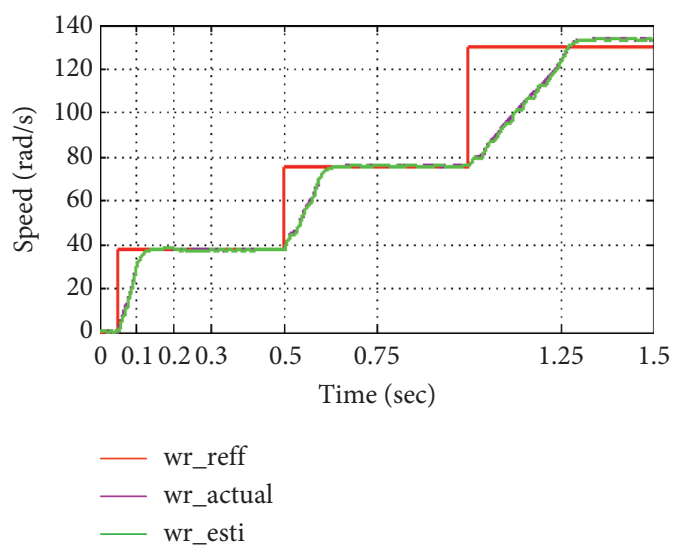

FIGURE 18: $50 \%$ increase of $R_{r}$ from its nominal value for different rotor speeds.

4.1.6. Regenerative Mode. Motor speed is changed from $+50 \mathrm{rad} / \mathrm{s}$ to $-50 \mathrm{rad} / \mathrm{s}$ keeping the load torque constant at $2 \mathrm{Nm}$. The drive is operated in the motoring mode up to 1 second. Thereafter, it enters in the regenerating mode of operation for 0.5 seconds and comes back to motoring region after 0.5 seconds. As shown in Figure 19, the estimated and the actual speed follow the reference speed successfully.
From Figure 20, due to the increase of stator current in that region, i.e., for 0.05 second, starting of the motoring region, and at 0.5 second, the operation enters to the regenerating mode, and finally, it turns back to the motoring mode after one second. The stator current increases for transient response and turns to their rate value for the steady state response.

Staircase tracking waveform includes the low speed region: a reference speed of $5 \mathrm{rad} / \mathrm{s}$ was initially applied at $t=0.05$ seconds, increased to $25 \mathrm{rad} / \mathrm{s}, 50 \mathrm{rad} / \mathrm{s}$, and $100 \mathrm{rad} /$ $\mathrm{s}$ at $t=0.5$ seconds, $t=0.75$ seconds, and at $t=1$ second, respectively. As shown in Figure 21, the estimated and the actual speed follow the reference speed with good accuracy, and it takes 0.09 seconds to track the reference speed at different levels of speed including the low speed region.

\section{Experimental Implementation}

To test the performance of the proposed scheme, experiment is carried out on the IM with the same parameters simulation. Experimental setup of the induction motor control developed system is shown in Figure 22, which is based on a high voltage motor control developer's kit produced by Texas Instruments Company. The PWM frequency for the experiment is $60 \mathrm{kHz}$, and the ISR frequency of $10 \mathrm{kHz}$ is selected for best operation of the motor. Experimental data 




FIgURE 19: The actual and estimated speed performance in the regenerative mode.

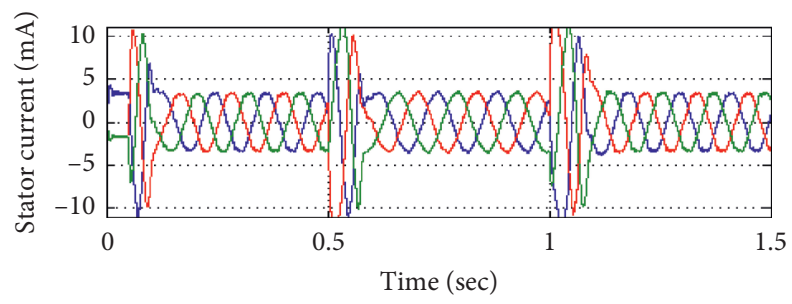

la
$-\mathrm{lb}$
$-\mathrm{lc}$

Figure 20: Stator current at motoring and regenerating modes.

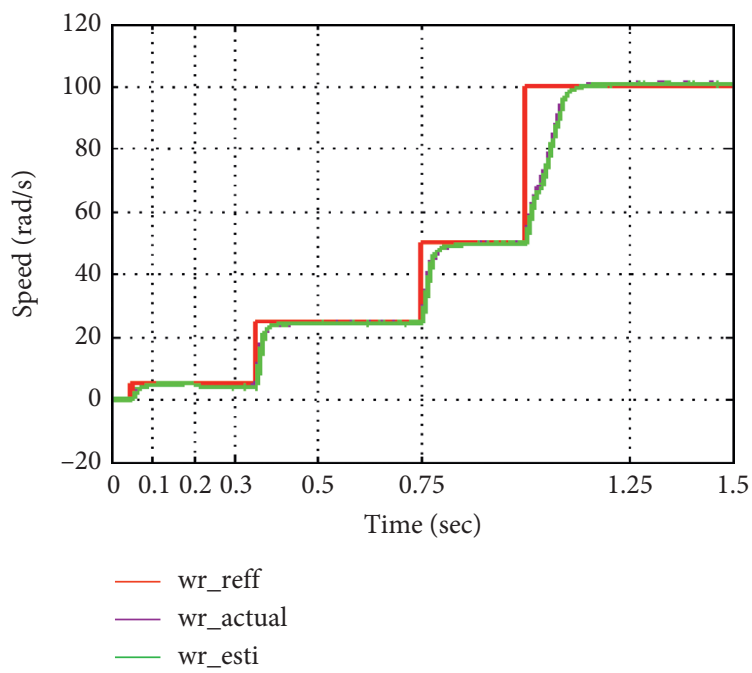

FIGURE 21: Speed response of staircase tracking waveform including the low speed region.

are captured for display and analysis via a graph tool in the Code Composer Studio (CCS).

The overall experimental system contains both hardware and software. The hardware includes the high voltage motor control kit with TMS320F28035 DSP control card, threephase induction motor, PC with Code Composer Studio (CCS v6.0) installed, digital oscilloscope, digital multimeter, JTAG probe, rheostat, and high voltage DC power supply.
The software includes different coordinate transformation algorithm, controller's algorithm, stator current-based MRAS speed estimator algorithm, space vector pulse width modulation algorithm, and the kit interrupt software algorithm. The overall experimental block diagram contains mainly three modules: Piccolo TMS320F28035 control card, high voltage motor control kit, and induction motor as shown in Figure 22. 


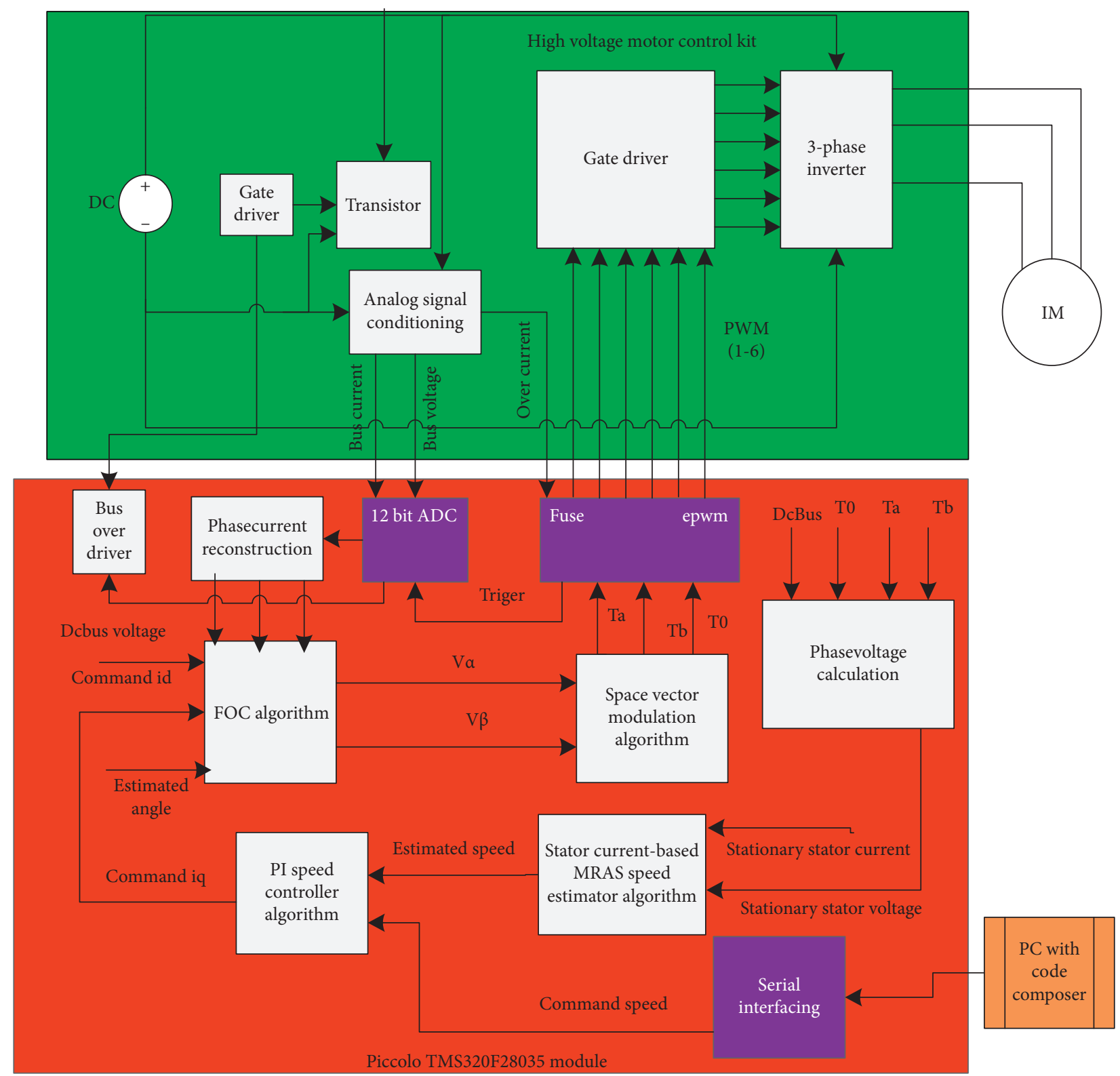

FIgURE 22: Experimental block diagram for MRAS-based sensorless speed control of the IM.

As shown in Figure 22, the high voltage motor control kit module includes gate driver, which controls the threephase voltage source inverter, analog signal conditioning circuit used to sense stator current and DC bus voltage, and three-phase invertor to drive the motor. The second module is Piccolo TMS320F28035 control card consisting of control algorithms and hardware module. Control algorithms include the FOC, PI speed controller, phase current and voltage reconstruction, stator current-based MRAS speed estimator, and SVPWM algorithm. The hardware modules are indicated by purple color in Figure 22.
The digital motor control software library is the collection of digital motor control software modules. The library supports the AC IM and comprises both peripheral dependent software drives and TMS320F28035 control card dependent modules.

The overall system algorithm is based on two modules as shown in Figure 23. These are the initialization module and interrupt subroutine module.

5.1. Experimental Setup. The experimental setup of the MRAS-based sensorless speed control of an induction motor is shown in Figure 24. The experimental setup includes the 

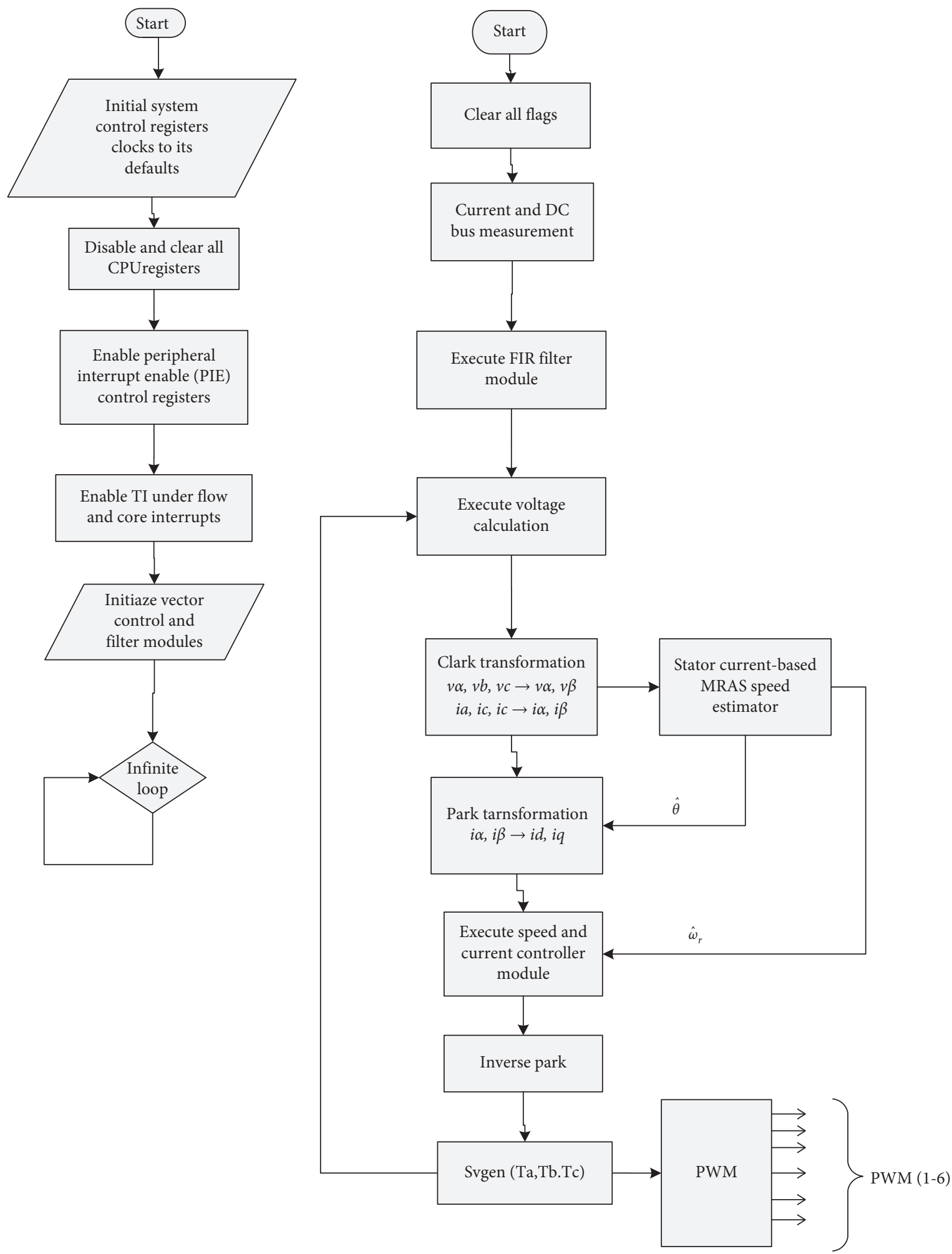

FIGURE 23: Flowchart of the proposed system. 


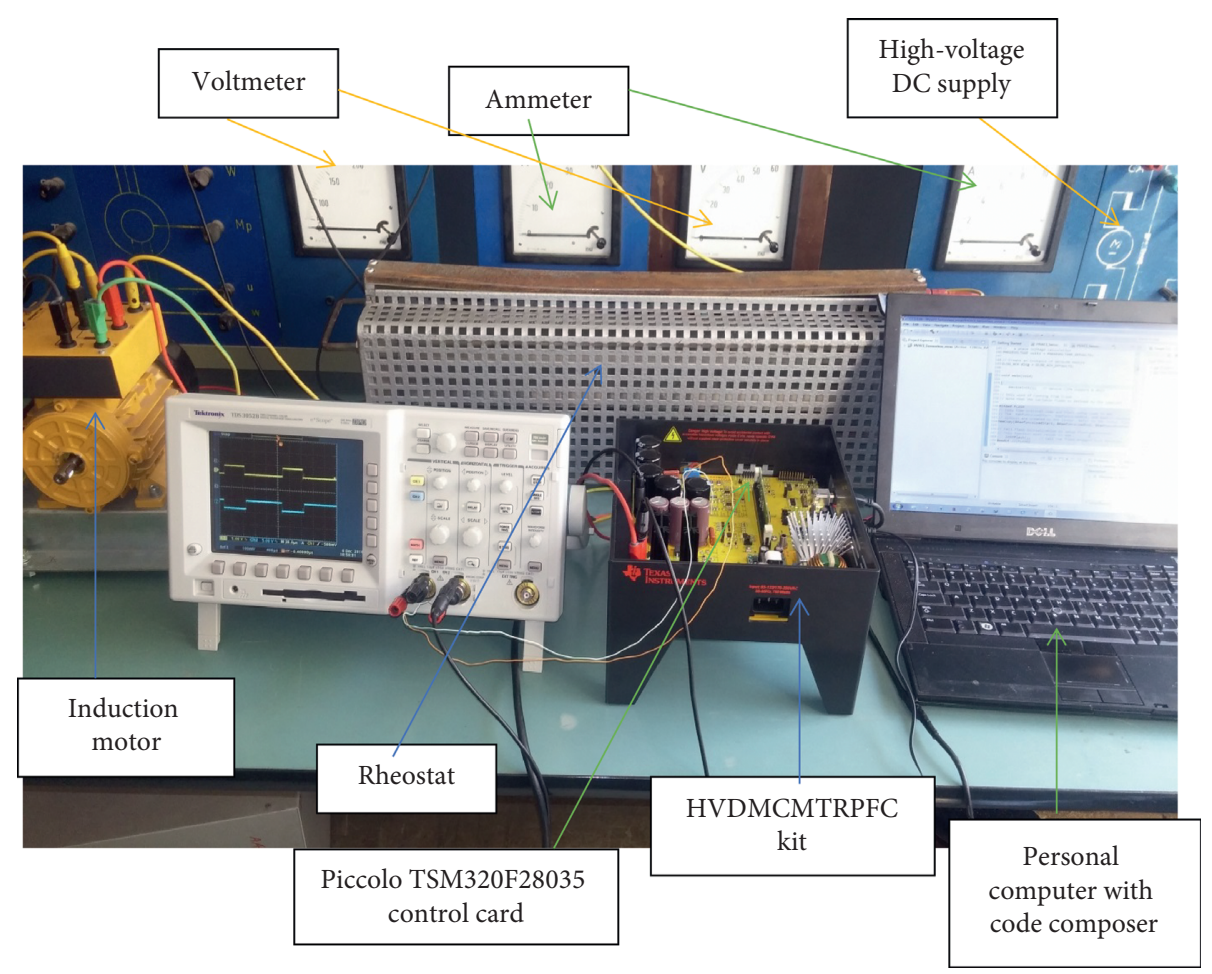

Figure 24: Experimental setup of the proposed system.
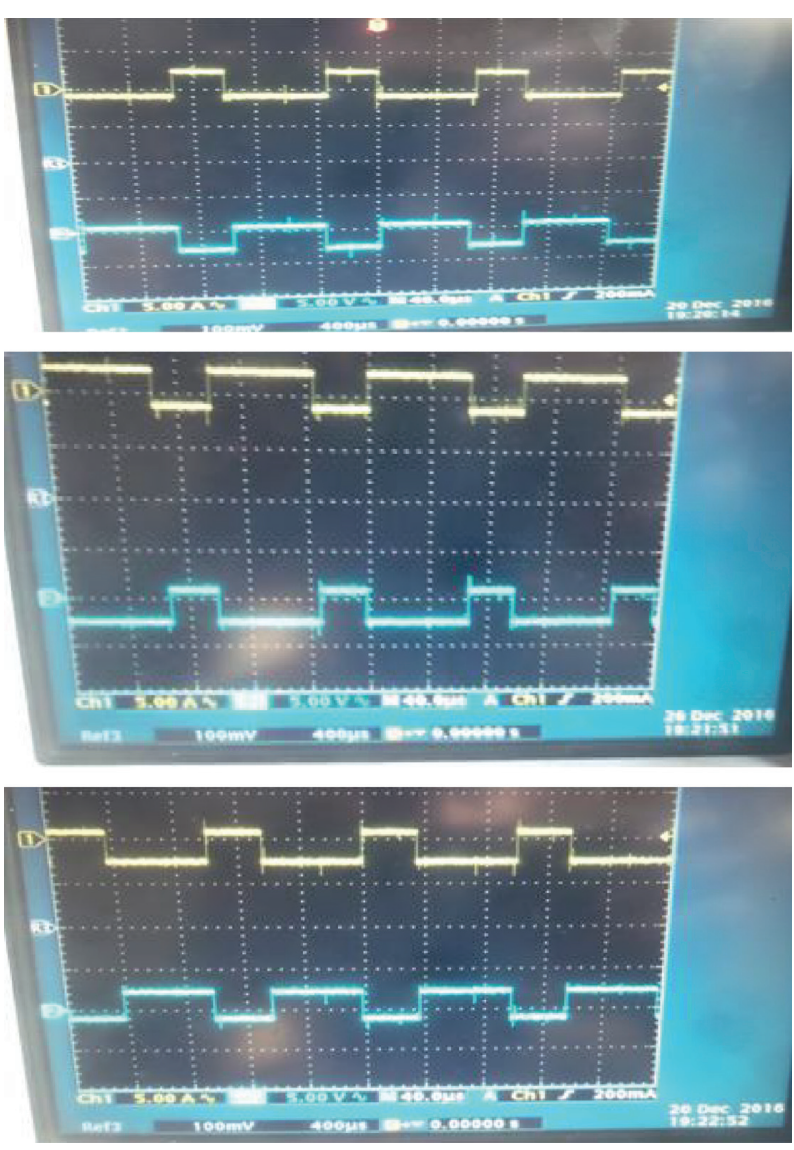

FIgURE 25: The six PWM output signals from DSP while the motor is running at $0.2 \mathrm{pu}$. 


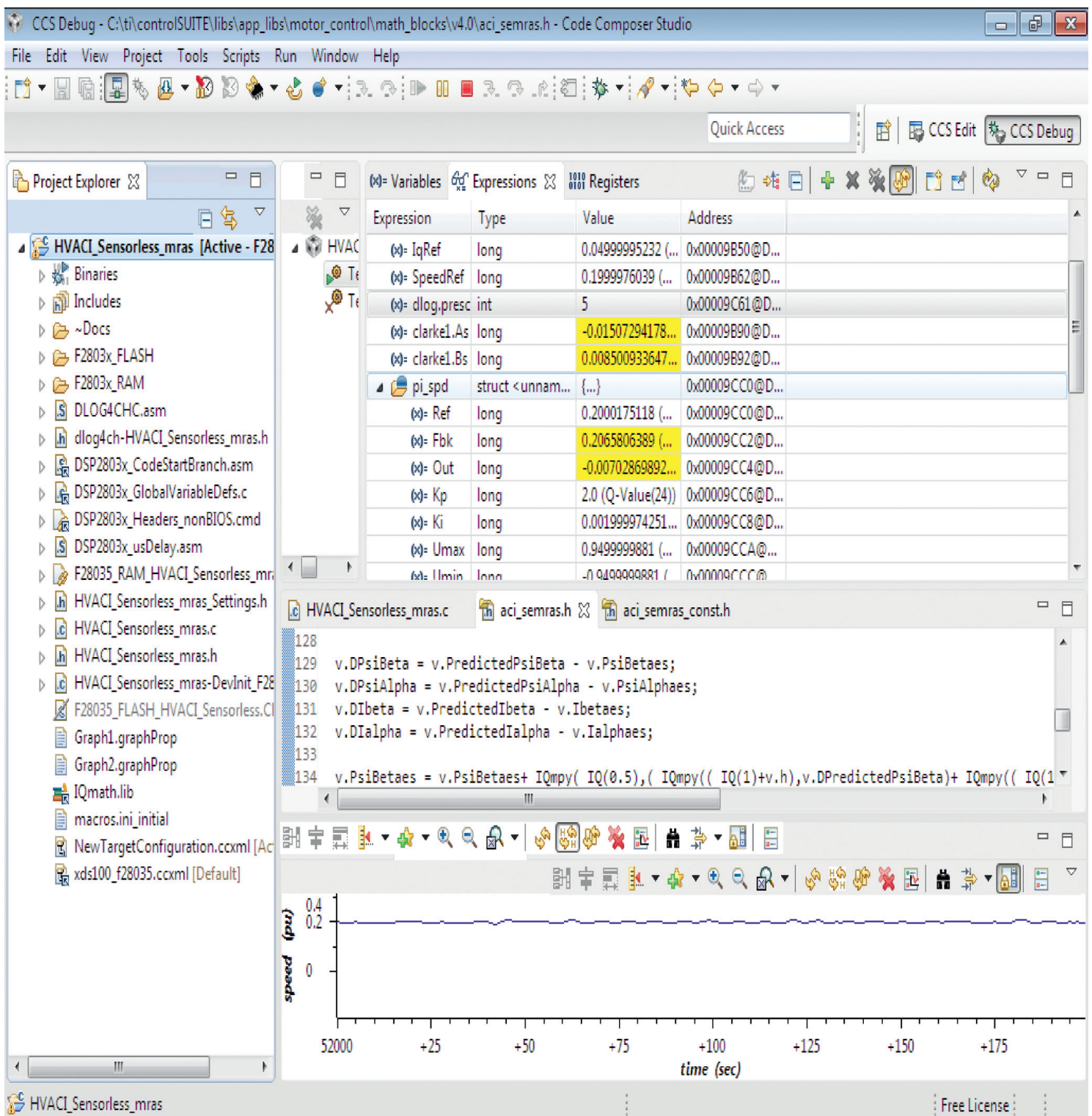

FIGURE 26: Snapshot of CCS programming interface while the motor is running at $0.2 \mathrm{pu}$.

host computer, which is used to program the system algorithm through Code Composer Studio v6.0. The HVDMCMTRPFC kit is connected with the host computer by a USB cable through the FTDI driver.

The source code on the host computer is debugged and loaded to the memory of the Piccolo TMS320F28035 control card through this cable. Controller power comprises of the $15 \mathrm{~V}, 5 \mathrm{~V}$, and $3.3 \mathrm{~V}$ that the board uses to power the control card and the logic and sensing circuit present on the board. This power can be sourced from auxiliary power supply module (M2). Auxiliary power supply module (M2) can generate $15 \mathrm{~V}$ and $5 \mathrm{~V}$ DC from rectified AC. DC bus power is the high voltage line that provides voltage for the inverter stage to generate three phases of $\mathrm{AC}$ voltage to control the motor. [Main]-BS5 and [Main]-BS6 are the power and ground connectors for this inverter bus, respectively.
5.2. Experimental Result. The main target in this experimental investigation is to control the motor at variable speed by generating the PWM signal, which generates the appropriate sinusoidal current on the stator of the motor through DSP. This makes the motor to rotate at the required speed and control the motor at different speeds including zero speed. The six PWM output signals are shown in Figure 25 while the motor is running at $0.2 \mathrm{pu}$.

It can be seen in Figures 26 and 27 that the induction motor tracks the desired speeds well in wide ranges, which demonstrate the effectiveness of the proposed scheme. From these, the rotor speed has been a good accuracy and almost similar with that of the simulation result shown in Figure 11. The implementation result shows that the stator current-based MRAS speed estimator can estimate the rotor speed with $0.00458 \mathrm{pu}$ of steady state error, and a good transient performance has been 


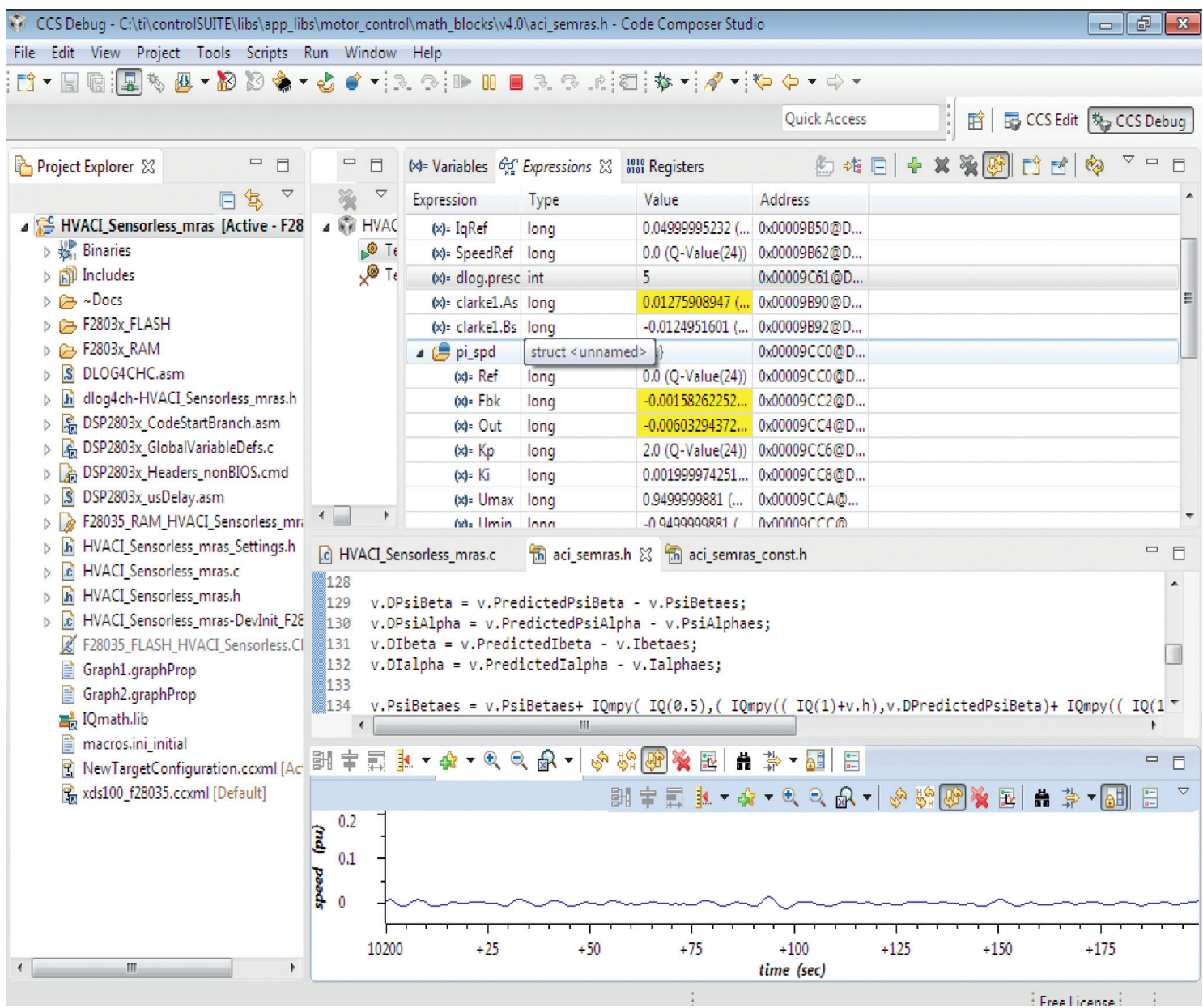

Figure 27: Rotor speed while the motor is running in a closed loop at $0.0 \mathrm{pu}$.

achieved. The implementation result shows that the stator current-based MRAS speed estimator can estimate the rotor speed with good performance of steady state and transient responses for sensorless speed control of the induction motor.

\section{Conclusion}

In this paper, design and implementation of the stator current-based MRAS speed estimator that overcomes the problem due to mechanical speed sensor and parameter sensitivity for speed control of IM have been investigated. The computational techniques used to simplify the stator currentbased MRAS speed estimator design and its implementation on Texas instrument TMS320F28035 control card are discussed. The simulation results show that stator current-based MRAS can estimate the rotor speed with a good performance speed, and the position error of $0.024 \mathrm{rad} / \mathrm{s}$ and $0.1 \mathrm{rad}$ for speed control of the induction motor has been achieved. As it is shown in Figure 8, the stator current-based MRAS speed estimator estimates the rotor speed of the induction motor with a steady state error of $0.028 \%$, and a good transient response with rise time of less than 0.1 second and settling time 0.15 second has been achieved. The performance of the stator current-based MRAS speed estimator was analyzed in terms of speed tracking capability, torque response quickness, low speed behavior, step response of drive with speed reversal, sensitivity to motor parameter uncertainty, and speed tracking ability in the regenerative mode. The system gives a good performance at no-load and loaded condition. Hence, it can work with different load torque conditions and with parameters variation. The closed loop experimental investigation is implemented using Texas instrument, PiccoloTMS320F28035 control card. Demonstration results in smooth speed control and with a maximum steady state error of $0.00458 \mathrm{pu}$, and a good transient response has been achieved.

\section{Data Availability}

The data used to support the findings of this study are available from the corresponding author upon request.

\section{Disclosure}

The paper is driven from the author's MSc thesis, available at http://etd.aau.edu.et/handle/123456789/4862.

\section{Conflicts of Interest}

The authors declare that they have no conflicts of interest. 


\section{Acknowledgments}

This work was supported by Addis Ababa University, Addis Ababa Institute of Technology in the School of Electrical and Computer Engineering.

\section{References}

[1] H. N. J. Senborg, Control of Electrical Machine Drives, pp. 316-345, John Wiley \& Sons, Hoboken, NJ, USA, 2011.

[2] M. Zaky, "Speed sensorless control of induction motor drives (review paper)," ACTA Electrothechnica, vol. 49, no. 3, pp. 221-228, 2008.

[3] J. W. F. A. D. Giaouris, "Controlled AC electrical drives," IEEE Trans. on Industrial Electronic, vol. 55, no. 1, pp. 1-11, 2008.

[4] C. L. a. H. G. F. S. Sedghizadeh, "Sensorless speed control of switched reluctance motor drive using the binary observer with online flux-linkage estimation," Iranian Journal of Electrical \& Electronic Engineering, vol. 5, no. 2, pp. 143-150, 2009.

[5] R. Blasco Giménez, High Performance Sensorless Vector Control of Induction Motor Drives, University of Nottingham, Nottingham, England, 1995.

[6] P. C. Krause and C. H. Thomas, "Simulation of symmetrical induction machinery," IEEE Transactions on Power Apparatus and Systems, vol. 84, no. 11, pp. 1038-1053, 1965.

[7] E. Radwan, N. Mariun, I. Aris, S. M. Bash, and A. H. Yatim, "IRFOC induction motor with rotor time constant estimation modelling and simulation," COMPEL - The International Journal for Computation and Mathematics in Electrical and Electronic Engineering, vol. 24, no. 4, pp. 1093-1119, 2005.

[8] K. Horváth and M. Kuslits, "Dynamic performance of estimator-based speed sensorless control of induction machines using extended and unscented kalman filters," Power Electronics and Drives, vol. 3, no. 1, pp. 129-144, 2018.

[9] M. Popescu, Induction Motor Modeling for Vector Control Purposes, Helsinki University of Technology Department of Electrical and Communications Engineering Laboratory of Electromechanics, Espoo, Finland, 2000.

[10] C. Ma, "Speed sensorless control of 3-phase induction motor using MRAS speed estimator," Theses and dissertations, Minoufiya University, Al Minufiyah, Egypt, 2003.

[11] M. N. Marwali and A. Keyhani, "A comparative study of rotor flux based MRAS and back EMF based MRAS speed estimators for speed sensorless vector control of induction machines," in Proceedings. of the IEEE-IAS Annual Meeting, pp. 160-166, New Orleans, LA, USA, October 1997.

[12] M. Rashed and A. F. Stronach, "A stable back-EMF MRASbased sensorless low-speed induction motor drive insensitive to stator resistance variation," IEE Proceedings - Electric Power Applications, vol. 151, no. 6, pp. 685-693, 2004.

[13] F. B. a. B. B. Wafa Bourbia, "Circle-criterion based nonlinear observer design for sensorless induction motor control," in Proceedings of the International Journal of Automation and Computing, Annaba, Algeria, December 2014. 